Halley's Conet.-In Circular No. 3 of the Transvaal Observatory Mr. Innes publishes the observations of the tail of Halley's comet recorded by himself, Mr. H. E. Wood, and Mr. WV. M. Worssell durings May 17-2I. Small sketches showing the form of the multiple tail at various times are also reproduced. In addition to the main tail there were two fainter glows separated by some degrees from the main stream near Pegasus, but reapproaching it in the neighbourhood of Aquila. Quite unexpectedly, as recorded by MIr. Payn and other observers, the remnants of the tails persisted in the eastern sky after the comet had passed the earth, and were seen each morning until the moon interfered, after May 21; but it was obvious that they were gradually fading away. On the morning of Mlay 20 the tail was traced to R.A. Igh., dec. $5^{\circ} \mathrm{S} ., 150^{\circ}$ from the invisible nucleus. In a letter to Mr. Innes, Mr. H. C. Reeve, of Lorentzville, states that at 5 a.m. on May 19 the magnificent main tail extended to the Milky Way, and its attendant shafts were respectively $15^{\circ}$ and $20^{\circ}$ long, giving the whole the appearance of a huge transparent cone into which the earth was rushing. On the evening of May 19 the whole comet was south of the ecliptic, yet on the morning of May 20 the original, branched tail was still west of the sun and north of the ecliptic.

Mr. Finlay and Prof. Rudge, at Bloemfontein, report having seen a rupture of the tail, near Aquila, take place on the morning of May is-19, but this was not recorded by any other observers.

Photographs of the comet were taken at the Transvaal Observatory, with the Franlilin-Adams star camera, on every possible occasion, and are to be discussed in a subsequent Circular; one of them is reproduced on a plate which. accompanies No. 4420 of the Astronomische Nachrichtcn. The chief characteristic of all the photographs is the complicated structure of the tail. Two groups of streamers are seen on either side of the axis, and, in addition, there are several side streamers showing links and irregularities; the photographs, in many points, resemble many of those taken of Morehouse's comet in $190 \mathrm{~s}$.

The Astronomische Nachrichten also contains notes from several Continental observatories generally confirming the results already published.

In the Comptes rendus for June 20 (No. 25 , p. 1659) 1I. J. Comas Sola gives a réstumé of the physical observations of the comet made, visually and photographically, with the $3 \mathrm{~S}-\mathrm{cm}$. refractor of the Fabra Observatory, during the periods of greatest brightness as a morning and as an evening object.

The comet beran to be perceptible to the naked eye, at Fabra, on April 15, and the length of the tail whilst near perihelion was about 50 million kilometres (31-2 million miles). There were distinct changes in all parts of the comet after its inferior conjunction with the sun.

Before conjunction the tail was generally bifurcated and made up of numerous long filaments, without knots or sharp bends; M. Sola suggests that this simple straight appearance was the resuit of the intense repulsive action of the sun while the comet was so near to it. The head was relatively small, although surrounded by very feeble and extensive envelopes; measurements of the photographs generally give $110,000 \mathrm{~km}$. (nearly 70,000 miles) as the diameter of the brightest part. Generally, the envelopes were eccentrically placed in regard to the axis of the tail, a feature which was very marked on May ir. The nucleus was very bright, and its diameter was about $3500 \mathrm{~km}$. (nearly 2200 miles).

After conjunction, the tail was not bifurcated; on May 30 it was like a brush of numerous short hairs, and from May 31 it appeared as an aigrette, which became modified from day to day. The bright part of the head was Iarger, its diameter being about $160,000 \mathrm{~km}$. (100,000 miles), bu the fainter envelopes were reduced. The nucleus at this time was very small, probably not more than $1000 \mathrm{~km}$. (625 miles) in diameter.

Measurements of the photographs of Mav 30 and 31 indicate that, within two million kilometres of the nucleus, the projected matter travelled at about $23 \mathrm{~km}$. per sec. In a previous note M. Sola referred to projections from the head into the tail, and to the doubling of the nucleus on
June 2 ; also to the appearance of several rapidly moving condensations on June 4. He now suggests that these appearances were a series of phosphorescent emanations which seemed to commence about Mlay 31 , and coincided with the change in the structure of the tail. Not wishing to state definitely the nature of these ejecta, he calls them glotes, and gives some measures of their apparent distances on June 4. Taking a mean, he finds for the velocity with which a globe receded from the nucleus, $527 \mathrm{~km}$. per second. All these globes appeared to vanish at a distance of about $25,000 \mathrm{~km}$. from the nucleus.

Observations of Wininecke's Comet (rgogd).-In No. $44^{20}$ of the Astronomische Nachrichten Herr R. Prager gives a number of positions of IVinnecke's comet observed with the 24 -inch refractor of the Santiago de Chile Observatory between November 2 and December 13, 1909 . At all times the comet was very faint, appearing as a circular patch of light $0.7^{\prime}$ in diameter, and having no tail or nucleus; after December 13 it was too faint to be seen.

Cololi of CoMet igloa DURING its P'ERIHElio: Passige.-Observed at the Transvaal Observatory on January 17 , the great comet $1910 a$ svas near the zenith, and therefore practically free from the colour-absorption effects of our atmosphere. Mr. Innes records that, under these conditions, it was identical in colour with, and almost indistinguishable from, the pure snowy-white, alto-cumulus clouds which were passing at the same time (Circular No. 3 , p. 21).

\section{THE INTERNATIONAL BOTANIC CONGRESS AT BRUSSELS}

THERE was a large and representative gathering of botanists in Brussels on the occasion of the International Botanical Congress on May 14-22. The inaugural meeting took place in the large rotunda at the Botanic Gardens, but the serious work of the congress was carricd out in the Salle des Fêtes in the grounds of the Exposition. The important subjects of deliberation were further consideration of the rules of systematic nomenclature and a series of propositions on phytogeographical nomenclature. The rules of systematic nomenclature which were drawn up as the result of the deliberations of the Vienna Congress in 1905 left open for future discussion special points in relation to non-vascular cryptogams and palacobotany. A number of sectional cominittees were appointed, and their recommendations formed the subject of debite at the recent congress. The chief matter for discussion was the starting points for nomenclature in the various groups. Was the date of publication of Linneus's "Species Plantarum," 1753, which had been adopted as the beginning of nomenclature for seed-plants and ferns, to be the universal starting point throughout the plant kinødom, or would it be preferable to take the date of publication of later systematic works dealing with the various groups of cellular cryptogams?

After some informal discussion among the workers in the groups in question, a series of recommendations was agreed to by the congress. The date 1753 was accepted as the starting point for the Mycetozoa, Alga (excepting certain groups to be noted belorv), Characex, Sphagnacex, Hepatica, and Lichens. The exceptions to the general rule for the Algx were as follows :-Desmids, J. Ralfs, "British Desmidiex," 1848; Oedogoniacex, K. E. Hirn, "Monographie u. Iconographie der Oedogoniacex," I900, Nostocacex, M. Gon'ont, "Nostocacées homocystées," I 890 , and E. Bornet and Flahault, "Nostocacées hétérocystées," I $886-S$.

For the Fungi, Fries "Systema Mycologicum," I $821-32$, was adopted as the point of departure, excepting for the Uredinea, Ustilaginea, and Gasteromycetes, which it was agreed should date from Persoon's "Synopsis," 1801. For Mosses, Hedwig's "Species Muscorum," ISoI, was agreed upon. In order to reduce to a minimum changes of names which would result in cases where an early date was adopted as a starting point, special committees were appointed for each of the large groups to draw up lists of nomina conservanda, or names of genera which, from iong-established use, should be retained, though inadmis sible on grounds of strict priority. These lists will be put NO. 2 I 22 , VOL. 83 ] 
before the next congress of 1915 ; in the meantime, workers are recommended to make as few changes as possible from generally accepted nomenclature. The discussion of a starting point for the nomenclature of Bacteria, and of the Schizophycex, excepting the Nostocacex, was postponed until the next congress of I9I5.

A useful decision was arrived at in connection with the names of pleomorphic fungi, the successive states of which have been described under different names. It was agreed that these should bear one generic and specific name, viz. the earliest given to the state, which it is agreed to call the perfect state, on condition that this name otherwise conforms to the rules. The "perfect state" is that which leads up to the ascus in the Ascomycetes, the basidium in the Basidiomycetes, the teleutospore in the Uredinex, and the spore in the Ustilaginex. The addition of figures, including microscopic details, was recommended when describing new genera or species of fungi.

In paloobotany some difficulty has arisen from the use of the same genus name for recent and fossil plants. In order to reduce to a minimum changes of name resulting from this cause, it was agreed to draw up a double list of generic names which are to be retained:-(1) a list of the generic names of living plants, duly published and in general use, which enter into competition with earlier names of fossil genera, such as Bucklandia; (2) a similar list of generic names of fossil plants which compete with earlier homonyms of living plants, which have been relegated to synonymy, in order to avoid the future use of such names for the living plant. In the former case the name of the living plant takes precedence, in the latter that of the fossil.

The palxobotanists showed some disinclination to fall into line with workers in descriptive botany generally in making use of a Latin diagnosis when describing new genera or species. It was, horvever, pointed out that a diagnosis, giving merely the important characters of the fossil in question, was required, and not a complete description; and, further, that such a diagnosis rendered the form in question far more widely intelligible than a description in a vulgar tongue. Those members who were present at Vienna in 1905 called to mind the difficulty experienced when attempting to limit the number and variety of vulgar tongues which should be admissible for the diagnosis of novelties. It was agreed that a Latin diagnosis should be given, with the recommendation to the author to add a full description in a vulgar tongue.

The last matter for discussion was the proposition to add to the list of nomina consersanda for seed-plants. The original list, which was agreed to by the Vienna Congress, was admittedly incomplete, but as it had been accepted and used for five vears many botanists were disinclined to amend it. A list of additions was proposed which, if accepted, would have upset again changes made since 1905 in conformity with the rules. On the other hand, the new list contained names of large and important genera, such as Persea, which could only be retained if included in a list of nomina conservanda-on strict grounds of priority they are inadmissible. It was decided to remove from the list those names of genera the inclusion of which would be subversive of changes already made, and with this important alteration the additions to the original list were agrced upon.

Dr. John Briquet, upon whom as Rapporteur-Général has fallen the brunt of the work of the section of systematic nomenclature, was persuaded to continue in office for the next five years until the congress of 1915 .

The Vienna Congress had also appointed a commission of eminent plant-geographers to draw up recommendations for phytogeographical nomenclature. The reporters of the commission, Profs. Flahault and Schroeter, drew up a report embodying their own views and those of other workers upon various aspects of the question, and also a series of recommendations based on the consideration of the views and suggestions put forward. These recommendations were accepted by a large majority of the commission, and formed the subject of debate at the congress. It was recognised that the congress should not attempt to pass laws or rules, but merely recommendations supported by reasoned annotations. It became evident, however, that a general agreement on the recommendations as a whole was not likely to be reached, and the reporters therefore decided to put before the congress only those recommendations upon which there appeared to be substantial agreement. The substance of these was as follows:-

(I) That every author should explain exactly what he understands by the terms he uses.

(2) That the popular names of units of vegetation in the various languages should be retained.

(3) That the principle of priority in phytogeographical terminology is inadmissible.

(4) That a polygot synonymic dictionary of phytogeographical terminology with bibliographical references should be compiled by a special commission.

(5) That the colour scheme suggested by Prof. Engler for maps of tropical vegetation be recommended for adoption.

(6) That ecological phytogeography may be defined as the study of the relationships of plants and plant-communities with their environment.

These recommendations were carried nem. con. As regards the somewhat contentious question as to the meaning and definition of the two terms plant-association and plant-formation which have come into use to designate the most important units of vegetation, Prof. Flahault stated that there appeared to be general agreement in considering the association as a unit of definite floristic composition and the formation as something different from the association.

Though it has not resulted in the establishment of a uniform system, the work of the commission has been of the greatest use in forcing workers to think about the concepts and terms they employ and in promoting international exchange of views; the promised synonymic dictionary will be invaluable.

An invitation to the congress to meet in London in $191_{5}$ was accepted.

At the conclusion of the congress many of the members went on to Berlin to visit the new Royal Botanic Garden and Mfuscum, at the invitation of the director; Prof. Adolf Engler. The spacious new gardens, with the commodious plant-houses, museum, and herbarium, which have been arranged by Dr. Engler at Dahlem, fifteen minutes by rai from Berlin, have replaced the older, smaller, and less convenient institution in the Grunwaldstrasse, Berlin. A special interest attaches to the gardens and museum at Dahlem. Starting de novo with the advantage as objectlessons of the great botanical institutions throughout the world, Dr. Engler has organised a garden and museum on thoroughly scientific lines, and embodying the ideas of a great systematist and plant-geographer. It was a great privilege to be conducted through the grounds and buildings by Dr. Engler, with the help of Prof. Urban, the assistant-director, and other members of the staff, and in the glorious summer weather which prevailed at the end of Niay the gardens showed to the best advantage. The arrangement is strictly scientific and educational, a small space only being devoted to mere ornamental gardening. A large portion is arranged on the lines of plant-geography. Here we find a representation of typical German forestland and other Central European formations, and, so far as space and climatic conditions permit, illustrations of the vegetation of widely different areas both in the Old and New Worlds. A most striking feature is the Alpine section, or Alpinum. Miniature mountain ranges have been thrown up, as far as possible to scale, and formed of the natural stone, and planted with the characteristic species and plant associations of the mountain area in question an attempt has also been made to indicate aititudinal distribution. The student is thus able to make himself acquainted by an object-lesson, to some extent, at any rate, with the flora of the Srviss Alps, the mountains of the Caucasus, or the Himalayas. Miniature streams and waterfalls add to the effect.

Another section is devoted to biology and morphology, while another forms a systematic teaching collection, with facilities to enable the student to work at the plants on the spot. Medicinal and economic plants have also their section. A great part of the area is devoted to the arboretum, a fine collection, though still young, as work on the gardens was only begun about fourteen years ago. The plant-houses include a fine tropical house illustrating

กO. 2 I22, VOL. 83 ] 
a tropical landscape, with a wonderful lawn of Sclaginclla Kraussiana, and forming the main feature in a four-sided series of smaller houses devoted especially to aroids, tropical dicotyledons, tropical orchids, other tropical monocotyledons, tropical ferns, various succulents, Cactacex-these last two forming a particularly fine collection-tropical economic plants, tropical water and marsh plants, Cape plants, subtropical Australian plants, and others; also a large temperature house and numerous culture houses. The museum contains a spacious herbarium and a number of fine exhibition galleries, including sections devoted to biology, systematic botany, palxobotany, plant-geography, and economic botany, also a section illustrating the products of the various German colonies. In addition there is a large lecture theatre, a laboratory, and a number of work-rooms. The whole forms a magnificent example of botanical organisation and enterprise.

On the following day opportunity was given for visiting the State School of Horticulture and the Biological Institute for Agriculture and Forestry, both adjoining the Botanic Garden.

An interesting and enjoyable meeting closed with a pleasant excursion on the IVannsee to Potsdam, arranged by the Union of Systematists and Plant-geographers. This included a visit to Sans-Souci and the Royal Park and Gardens under the guidance of Director Fintelmann.

A. B. R.

\section{AN ENGLISH PHILOSOPHICAL CONGRESS.}

iN Friday and Saturday last, June 24 and 25 , joint meetings of the Aristotelian Society, the British Psychological Society, and the Mind Association were held at 22 Albemarle Street, London, at which subjects of wide philosophical and psychological importance were discussed before large and interested audiences. The discussions were based upon papers previously printed and circulated among the members of the several societies. On Friday afternoon the problem of "Instinct and Intelligence" was considered on the basis of papers by Messrs. C. S. Myers, C. Lloyd Morgan, H. WVildon Carr, G. F. Stout, and IVm. MrDougall; Saturday morning was devoted to the discussion of the question, "Are Secondary Qualities Independent of Perception?" on the basis of papers by Mlessrs. T. Percy Nunn and F. C. S. Schiller; and the congress was brought to a close on Saturday afternoon with papers on the nature and development of attention, by Mr. G. Dawes Hicks; the "faculty" doctrine: outline of some experiments on school children in relation to this doctrine, by .Ir. IV. H. Winch; and some observations on the asthetic appreciation of colour combinations, by Mr. E. Bullough.

\section{1.-Instinct and Intelligence.}

Dr. C. S. Myers maintained the view that instinct and intelligence are inseparable in all forms of mental activity, animal and human alike; that they are respectively the objective and subjective aspects of the same thing, viz. mental process in general and in its various particular manifestations; and that instinctive behaviour, while characterised by mechanism in its objective aspect, is from the point of view of the experiencing subject characterised by finalism. He criticised the two assumptions common'y made with regard to instinct as a form of mental process distinct from intelligence, viz. that in instinctive behaviour as such there is no awareness in the individual's consciousness of the end to be achieved, and that such behaviour is fixed and from the beginning perfect. He pointed out that an instinct is to bc distinguished from a mere reflex or chain of reflexes by (1) a feeling of activity, and (2) a vague awareness of the result of the instinctive action before the action is actually performed, both characteristics being present in the very first manifestation of the instinct. These rudiments of conation and meaning are essential constituents of any activity deserving the characterisation "instinctive." Observations of instinctive activities in insects and other animals do not justify the view that such activities are "perfect the very first time," or that they exhibit undeviating uniformity; " even ants are capable of learning from their elders," and this power is generally regarded as a sign of intelligence. The common view that man has few instincts compared with the lower animals is partly accountable for by the fact that "he is never aware that he is acting instinctively." His inner or subjective acquaintance with those activities pronounces them to be of the nature of intelligence.

Lastly, from the more general points of view of evolution and philosophy, the finalistic interpretation of the evolution of mind, and indeed of the entire universe, is the necessary complement and essential correlative of the mechanical interpretation, if our thought is to be saved from that pure abstraction-purposeless mechanism.

In conclusion, neither are instincts identifiable with refiexes, nor do they form a third class in addition to those of reflexes and intelligence. Summing up in Dr. Myers's own words:- "According to my view and my use of the words, instinct regarded from within becomes intelligence; intellifence resarded from without becomes instinct."

Prof. Lloyd Morgan agreed with Dr. Mfyers so far as to adnit that the two factors, instinct and intelligence, "are present in the most intimate relationship throughout very nearly the whole range of animal behaviour as exhibited by those organisms in which the central nervous system has reached a sufficiently high level of development and differentiation to justify the use of the words "instinctive' and 'intelligent." In his view, "the instinctive factors depend entirely on how the nervous system has been built up through heredity under that mode of racial preparation which we call evolution; intellisent behaviour depends also on how the nervous system has been modified and moulded in the course of that individual preparation which we call the acquisition of experience." (Dr. Myers suggested in the course of the discussion that this was genetic rather than psychological analysis.)

Prof. Lloyd Morgan illustrated his views by means of a somewhat detailed account of the experience of a young moorhen chick, and gave as a brief definition of instinctive behaviour, behaviour which is "practically serviceable on the occasion of its first performance," thus including within its scope reflex action so far as this is accompanied by consciousness. He also referred to the behaviour of the Yucca moth, and to the stinging of prey by the solitary wasps, as instances of instincts performed once only in the lifetime of the individual, where learning by imitation, S.c., was impossible. He considercd that the element of intelligence supervened in originally instinctive behaviour by the introduction of "meaning" through "factors of revival," though he emphasised the fact that "this is every whit as much the outcome of the innate potentiality of the moorhen as the originally instinctive performance." If instinct be identified with innate potentiality, all intelligent behaviour involves an instinctive element.

MIr. H. Wildon Carr considered the problem from the philosophical standpoint, and gave a detailed exposition of Bergson's views, which he supported by arguments for the most part metaphysical. He refused to identify natural dispositions or tendencies with instinct, and for this reason found himself unable to agree with Dr. Myers's view. He emphasised the contrast between the very complicated instinctive activities of ants, bees, \&c., many of which cannot by any possibility have been learnt by individual expericnce, and the more pronounced cases of intelligence in man, and, reminding his audience that "instinct and intelligence are not observable facts, but interpretations," proceeded to show how the troo terms represent two distinct lines of evolution of animal life, along each of which there is to be found no tendency towards evolution in the direction of the other. Along one, instinct evolves at the expense of intelligence; along the other, intelligence evolves at the cxpense of instinct. "The fundamental difference is one of kind, and lies in the mode of apprehension of reality, and the kind of knowledge that serves the activity of each. It is this essential difference that accounts for the desree of consciousness or unconsciousness, plasticity or fixity that characterises each, and not vice zersa.... It is not a scientific but a metaphysical distinction, which rests on a criticism of the nature and limitations of intel-

NO. 2122 , VOL. $\left.8_{3}\right]$ 